\title{
Los espaciadores hechos en casa fueron útiles en el asma agudo infantil
}

Home-made spacers for bronchodilator therapy in children with acute asthma: a randomised trial. Zar HJ, Brown G, Donson $\mathrm{H}$ y col. Lancet 1999 Sep 18;354:979-82

\section{Objetivo}

Comparar la eficacia de espaciadores caseros con el espaciador convencional para administrar $\beta 2$ agonistas a chicos con asma agudo.

\section{Diseño}

Ensayo clínico aleatorizado

Lugar

Departamento de pediatria, Universidad de Cape Town, Sudáfrica.

\section{Pacientes}

Se incluyeron 88 chicos de 5 a 13 años con síntomas de obstrucción y flujo espiratorio pico (FEP) $<80 \%$ del valor normal.

\section{Intervención}

Se randomizaron en cuatro grupos para recibir fenoterol en aerosol mediante diferentes espaciadores: 1)espaciador convencional con pieza bucal (tiene válvula y $145 \mathrm{ml}$ ), 2) espaciador hecho con botella plástica de $500 \mathrm{ml}$ sellando el agujero del aerosol con pegamento, 3) espaciador hecho con botella plástica de $500 \mathrm{ml}$ sin sellado y 4) una copa de $200 \mathrm{ml}$ de poliestireno con agujero para el aerosol en la base. La copa se usó sobre nariz y boca simulando una máscara facial. El pico de las botellas se usó como pieza bucal. La dosis de fenoterol fue $400 \mu \mathrm{g}$ para menores de $25 \mathrm{~kg}$ y $600 \mu \mathrm{g}$ para los mayores. Se recomendó realizar una respiración normal (volumen corriente) y no se intentó sincronizar el disparo con la inspiración.

Medición de resultados

Se les realizó puntaje clínico, prueba de función pulmonar y sa- turometría inmediatamente antes de realizar el puff y luego de 15 minutos. Si el niño tenía un PEF menor de $70 \%$ se le realizaba una nebulización con fenoterol.

\section{Resultados principales}

El puntaje clínico mejoró en los 4 grupos. Los 4 tipos de espaciadores fueron efectivos ya que la mediana de mejoría en el PEF fue mayor a $15 \%$ en todos. La mejoría en el VEF1 fue mayor en los grupos 1,2 y 3 que en el de la copa $(p=0.02)$. El uso de espaciadores produjo una mejoría importante en el PEF, la capacidad vital forzada y el flujo medio forzado (VEF25-75\%). EI espaciador convencional y la botella sellada tuvieron mejorías similares, la botella sin sellado tuvo mejorías intermedias y la copa fue la menos efectiva. Requirieron nebulización 7 pacientes tratados con espaciador convencional, 9 con botella sellada, 12 con botella sin sellado y 12 con copa. La mejoría en el VEF1 y PEF luego de la nebulización fue mínima en los grupos 1 y 2 (porcentajes de cambio menores al 6\%) pero fue marcada en los que habían usado la copa. Los que usaron botella no sellada tuvieron un pequeño incremento en el VEF1 y en el PEF luego de la nebulización. No hubo cambios en la saturación de oxígeno en ningún chico. Un $25 \%$ tuvo reacciones adversas. No hubo asociación entre el tipo de espaciador y el desarrollo de efectos adversos.

\section{Conclusiones}

El espaciador convencional y la botella sellada producen similar broncodilatación. La botella sin sellado da una mejoría intermedia de la función pulmonar y la copa es la menos efectiva como espaciador. El uso de botella espaciadora debe ser incorporado a las normas de asma en los países en desarrollo.

\section{Comentario}

Los espaciadores facilitan el uso de los inhaladores, reducen la absorción sistémica y los efectos adversos de los corticoides inhalados ${ }^{1,2}$. Los autores fabricaron espaciadores con botellas de medio litro. Les hicieron un agujero en la base con un alambre caliente con la forma y el tamaño de la boquilla plástica del inhalador. Esta parte era insertada inmediatamente para lograr una unión estrecha con el plástico caliente de la botella (aún en el espaciador no sellado). Las botellas eran preparadas con 15 disparos del aerosol para reducir la carga aerostática de las paredes y optimizar la liberación de droga. A diferencia del espaciador convencional, las botellas no tienen válvula y el aire exhalado puede entrar en ellas y diluir el fármaco. Por este motivo se usó una dosis elevada de fenoterol (2 a 3 veces la dosis usual), aunque el hecho de que un cuarto de los pacientes presentara efectos adversos hace pensar que las botellas son más eficaces de lo que parece. El tamaño de la muestra, aunque pequeño, fue adecuado para detectar un cambio de $15 \%$ o más en el PEF con un $90 \%$ de poder ${ }^{*}$, lo cual es clínicamente razonable y estadísticamente correcto.

Los autores demostraron la eficacia de los espaciadores caseros para el uso de agonistas $\beta 2$ en la crisis aguda, aunque es probable que también sean útiles en la administración de los corticoides inhalados en el manejo del asma crónico. Resta saber si también será necesario modificar las dosis usuales. Lamentablemente, la copa no sirvió tan eficazmente como máscara facial, con lo que los menores de 2 años que la necesitan no se beneficiarán.

Los resultados de este trabajo son importantes especialmente para países en desarrollo, ya que sustentan con evidencia de buena calidad una práctica empírica que mejora la calidad a bajo costo.

\section{Dr. Juan Pablo Mouesca [ Pediatra. Clínica Monte Grande ]}

\footnotetext{
Referencias

Estrategia global para el manejo y prevención del asma. Instituto nacional del corazón pulmón y sangre/ OMS. 1995.

2. Mallol J. Aerosolterapia en lactantes y niños. En: Pediatría Meneghello. Panamericana. $5^{\circ} \mathrm{Ed}$. 1997:1387-9.
} 